\title{
How to diagnose cervicogenic dizziness
}

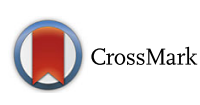

\author{
Alexander S. Reiley, Frank M. Vickory, Sarah E. Funderburg, Rachel A. Cesario and Richard A. Clendaniel
}

\begin{abstract}
Cervicogenic dizziness (CGD) is a clinical syndrome characterized by the presence of dizziness and associated neck pain. There are no definitive clinical or laboratory tests for CGD and therefore CGD is a diagnosis of exclusion. It can be difficult for healthcare professionals to differentiate CGD from other vestibular, medical and vascular disorders that cause dizziness, requiring a high level of skill and a thorough understanding of the proper tests and measures to accurately rule in or rule out competing diagnoses. Consequently, the purpose of this paper is to provide a systematic diagnostic approach to enable healthcare providers to accurately diagnose CGD. This narrative will outline a stepwise process for evaluating patients who may have CGD and provide steps to exclude diagnoses that can present with symptoms similar to those seen in CGD, including central and peripheral vestibular disorders, vestibular migraine, labyrinthine concussion, cervical arterial dysfunction, and whiplash associated disorder.
\end{abstract}

Keywords: Cervicogenic dizziness, Cervical dizziness, Disequilibrium, Vertigo, Cervical spine, Cervical proprioception, Whiplash, Diagnosis

\section{Background}

CGD was first described as 'cervical vertigo' by Ryan and Cope in 1955, and has at times been considered a controversial diagnosis [1]. The condition has also been named proprioceptive vertigo, cervicogenic vertigo, and cervical dizziness; however, since true vertigo is rarely a symptom seen in people with CGD, it is now generally termed cervicogenic dizziness [2].

Cervicogenic dizziness is characterized by the presence of imbalance, unsteadiness, disorientation, neck pain, limited cervical range of motion (ROM), and may be accompanied by a headache $[2,3]$. The cervical spine may be considered the cause of the dizziness when all other potential causes of dizziness are excluded. To be considered CGD, dizziness should be closely related to changes in cervical spine position or cervical joint movement [4]. Although the etiology remains unknown, many cases of CGD have been diagnosed post whiplash injury, or have been associated with inflammatory, degenerative, or mechanical dysfunctions of the cervical spine $[5,6]$.

What causes the symptoms of imbalance, unsteadiness, and disorientation is not fully understood. Some have suggested the presence of faulty cervical proprioceptive inputs as a contributing factor [7]. It has been proposed

\footnotetext{
* Correspondence: areileypt@gmail.com

Doctor of Physical Therapy Division, Duke University, 2200 W Main St. Durham, NC 27705, USA
}

that a disruption of the normal afferent signals from the upper cervical proprioceptors to the vestibular nucleus results in an inaccurate depiction of head and neck orientation in space [8]. Another possible cause of these abnormal afferent signals is pain [6].

At present, CGD is a diagnosis of exclusion. A diagnosis of exclusion exists in situations where no single test is able to diagnose the condition, and the diagnosis cannot be verified by outcomes, imaging, laboratory values, or unique signs and/or symptoms [9]. Diagnoses of exclusion are challenging for health practitioners because they require high levels of clinical skill and a strong understanding of the sequencing of proper tests and measures needed to rule out or rule in competing diagnoses. There are many causes of dizziness, including numerous medications and a diverse assortment of vestibular, cardiovascular, metabolic, neurological, psychological, and vision problems. Therefore, a thorough, stepwise process for excluding diagnoses with symptom presentation similar to CGD would be a clinically useful tool for the differential diagnosis of CGD.

Reneker and colleagues [10] conducted a Delphi study to assess the perceived utility of different clinical tests for differentiating between cervicogenic and other causes of dizziness after a sports-related concussion. The authors found no consensus among health practitioners regarding the appropriate tests to identify CGD. The lack of consensus regarding the tests for CGD was cross-professional. 
Considering the enigmatic nature of CGD, a systematic process is a pragmatic tool for differential diagnosis of CGD. The aim of this narrative is to provide a stepwise process toward the diagnosis of CGD, with utilization of a rule out, rule in paradigm. The determination of which assessment tools to utilize and the order in which the examination is performed is at the discretion of the clinician.

\section{Main text}

Our proposed clinical reasoning stepwise process for diagnosing CGD is depicted in Fig. 1. To rule out competing diagnoses, one needs tests that have low negative likelihood ratios (LR-) and subsequent high sensitivity in order to decrease the post-test probability of the condition when the finding is negative. In contrast, tests that have high positive likelihood ratios $(\mathrm{LR}+)$ and subsequent high specificity are used to rule in a condition. The sensitivities, specificities, and likelihood ratios of relevant tests are listed in Table 1. Descriptions and explanations of the tests are listed in Table 2. The background information and details of each step are presented in the following sections.

\section{Stepwise process for diagnosing cervicogenic dizziness Step 1: Patient history}

In order to determine whether a patient potentially has CGD, it is essential to clarify the symptoms and nature of onset. For CGD to be considered, the patient should have a history of neck pathology and also experience dizziness that has a close temporal relationship with the onset of cervical spine symptoms. Cervicogenic dizziness should not be considered if the patient does not have neck pain. The neck pain can occur at rest, with movement, or with palpation. Symptoms caused by CGD should be exacerbated by movements that elicit neck pain and should subside with interventions that alleviate neck pain.

It is imperative to obtain a thorough patient history as the first step in the diagnostic process in order to identify red flags, to begin ruling out competing pathologies, and to prioritize pathologies that best fit the description of the onset, signs, and symptoms. Table 3 details the typical clinical presentations of CGD and the pathologies that can present with similar symptoms. Important information to seek for patients with both dizziness and neck pain includes presence of cardiovascular risk factors, history of migraines, symptoms of tinnitus or aural fullness, oscillopsia, and symptoms exacerbated by exertion, positional changes, busy environments, or specific activities.

The nature of the patient's symptoms can aide in determining the cause of dizziness. It is important to clarify the quality of the reported "vertigo" or "dizziness," as there is significant inconsistency in the use of these terms.
Dorland's Illustrated Medical Dictionary [11] defines vertigo as an illusion of movement; a sensation as if the external world were revolving around the individual (objective vertigo), or as if the individual were revolving in space (subjective vertigo). Vertigo is not a symptom arising from the cervical spine, but rather is caused by peripheral vestibular disorders or lesions within the vestibular pathways of the central nervous system.

The duration of symptoms is another important aspect of the subjective history that helps differentiate CGD from other pathologies. The duration of symptoms for CGD can range from days to months to years. Each episode of dizziness typically lasts minutes to hours [3]. The typical duration of symptoms for each pathology discussed can be found in Table 3 .

There are numerous vestibular causes of dizziness with characteristic presentations that can help distinguish each from CGD. Ménière's disease is a chronic vestibular disorder characterized by episodic bouts of aural fullness, vertigo, and hearing loss $[12,13]$. Cervicogenic dizziness however, typically does not include aural fullness, tinnitus, or hearing loss. The presence of these symptoms does not definitively rule in Ménière's disease, but does decrease the likelihood that CGD is implicated.

Benign paroxysmal positional vertigo (BPPV) is the most common vestibular pathology. BPPV occurs when calcium carbonate crystals (otoconia) become dislodged from the utricle and migrate into one of the three semicircular canals located within the inner ear. BPPV presents as vertigo associated with changes in head position relative to gravity. The vertigo associated with BPPV is accompanied by nystagmus. The most common pattern of nystagmus seen in BPPV is a mixed up-beating and torsional nystagmus, but the direction of the nystagmus will vary depending on which semicircular canal is affected. If a patient has symptoms of vertigo accompanied by nystagmus in response to changing head position in space, then BPPV is more likely than CGD. In a study comparing BPPV to CGD, sensations of "drunkenness" and "fainting" were found in both groups, however these symptoms were reported significantly more frequently by the CGD group than the BPPV group, whereas rotatory sensation and symptom duration lasting only a few seconds were significantly more common in the BPPV group [14]. Cervical neck movement, fatigue, anxiety, and stress were also found to be more common precipitating factors for exacerbation of symptoms in the CGD group as compared to the BPPV group.

A patient with an acute, unilateral, peripheral vestibular loss due to labyrinthitis or vestibular neuronitis will generally present with marked vertigo and imbalance, with associated nausea and possibly vomiting. In addition, the patient will acutely present with spontaneous horizontal, direction fixed nystagmus in room light. As the acute 


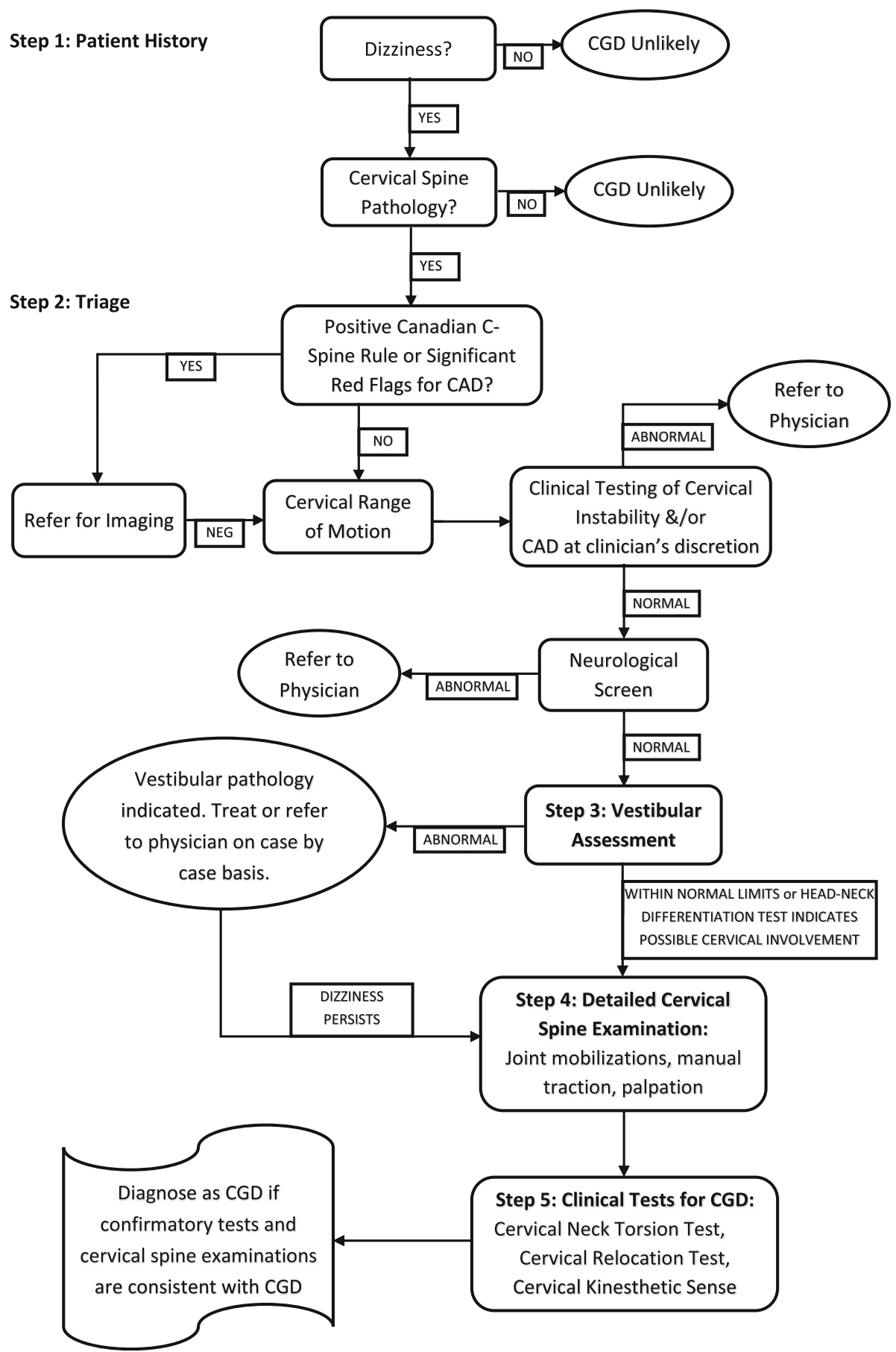

Fig. 1 Stepwise algorithm for diagnosing cervicogenic dizziness

signs and symptoms dissipate, the patient may be left with a variety of symptoms, including dizziness, motion sensitivity, imbalance, difficulty with concentration, tinnitus, and hearing loss [15]. The subjective report is useful in differentiating vestibular loss from CGD because patients with CGD typically do not have tinnitus, hearing loss or vertigo.
Vestibular migraines have been described as the most common cause of recurrent vertigo [16]. Refer to Table 3 for the specific criteria developed by The International Headache Society to diagnose a vestibular migraine. Key symptoms frequently present in vestibular migraine, but not CGD, are aura, true vertigo, throbbing headaches, sensitivity to auditory or visual sensory stimulation, and 
Table 1 Diagnostic accuracy of tests

\begin{tabular}{|c|c|c|c|c|c|c|c|c|}
\hline Test & Diagnosis & $\begin{array}{l}\text { Sensitivity } \\
(\%)\end{array}$ & $\begin{array}{l}\text { Specificity } \\
(\%)\end{array}$ & $\begin{array}{l}\mathrm{PV+} \\
(\%)\end{array}$ & $\begin{array}{l}\text { PV- } \\
(\%)\end{array}$ & LR+ & LR- & Reference \\
\hline Canadian C-Spine Rule & $\begin{array}{l}\text { Cervical Spine } \\
\text { Trauma }\end{array}$ & 99 & 45 & 6.03 & 100 & 1.81 & 0.01 & $\begin{array}{l}\text { Stiell et al. [36]; Duane } \\
\text { et al. [37] }\end{array}$ \\
\hline Cervical Arterial Dysfunction (CAD) Test & CAD & $0-57$ & $87-100$ & $0-100$ & $26-96$ & $\begin{array}{l}0.22- \\
83.3\end{array}$ & $\begin{array}{l}0.44- \\
1.4\end{array}$ & $\begin{array}{l}\text { Hutting et al. [22]; } \\
\text { Petersen et al. [38] }\end{array}$ \\
\hline Sharp Purser Test & $\begin{array}{l}\text { Transverse } \\
\text { Ligament Stability }\end{array}$ & 69 & 96 & 85 & 90 & 15.6 & 0.33 & $\begin{array}{l}\text { Uitvlugt \& Indenbaum } \\
\text { [39]; Hutting et al. [40] }\end{array}$ \\
\hline Alar Ligament Test & $\begin{array}{l}\text { Alar Ligament } \\
\text { Stability }\end{array}$ & $\begin{array}{l}\text { Right: } 69 \\
\text { Left: } 72\end{array}$ & $\begin{array}{l}\text { Right: } 100 \\
\text { Left: } 96\end{array}$ & $\begin{array}{l}\text { Right: } \\
100 \\
\text { Left: } \\
93\end{array}$ & $\begin{array}{l}\text { Right: } \\
80 \\
\text { Left: } \\
81\end{array}$ & - & - & Kaale et al. [41] \\
\hline Dix-Hallpike & $\begin{array}{l}\text { Posterior Canal } \\
\text { BPPV }\end{array}$ & 79.3 & 75 & 95.8 & 33.3 & 3.17 & 0.14 & Halker et al. [42] \\
\hline Head Thrust Test & $\begin{array}{l}\text { Unilateral Vestibular } \\
\text { Hypofunction }\end{array}$ & $\begin{array}{l}71 \text { (88 for } \\
\text { complete } \\
\text { loss) }\end{array}$ & 82 & 87 & 65 & 4.16 & 0.3 & Schubert et al. [43] \\
\hline Manual Spinal Examination & $\begin{array}{l}\text { Cervical Facet Joint } \\
\text { Dysfunction }\end{array}$ & 92 & 71 & - & - & 3.17 & 0.11 & Schneider et al. [30] \\
\hline Palpation for Segmental Tenderness & $\begin{array}{l}\text { Cervical Facet Joint } \\
\text { Mediated Pain }\end{array}$ & 94 & 73 & - & - & 3.48 & 0.08 & Schneider et al. [30] \\
\hline Cervical Neck Torsion Test & $\begin{array}{l}\text { Cervicogenic } \\
\text { Dizziness (versus } \\
\text { BPPV) }\end{array}$ & 72 & 92 & - & - & 9 & 0.3 & $\begin{array}{l}\text { L'Heureux-Leabeau } \\
\text { et al. [14] }\end{array}$ \\
\hline $\begin{array}{l}\text { Cervical Relocation Test (with positive test } \\
\text { defined by any of the } 4 \text { positions with JPE } \\
>4.5^{\circ} \text { ) }\end{array}$ & $\begin{array}{l}\text { Cervicogenic } \\
\text { Dizziness (versus } \\
\text { BPPV) }\end{array}$ & 92 & 54 & - & - & 2 & 0.15 & $\begin{array}{l}\text { L'Heureux-Leabeau } \\
\text { et al. [14] }\end{array}$ \\
\hline $\begin{array}{l}\text { Cervical Relocation Test (with positive test } \\
\text { defined by mean JPE }>4.5^{\circ} \text { ) }\end{array}$ & $\begin{array}{l}\text { Cervicogenic } \\
\text { Dizziness (versus } \\
\text { BPPV) }\end{array}$ & 72 & 75 & - & - & 2.9 & 0.37 & $\begin{array}{l}\text { L'Heureux-Leabeau } \\
\text { et al. [14] }\end{array}$ \\
\hline Smooth Pursuit Neck Torsion (SPNT) Test & $\begin{array}{l}\text { CGD in people with } \\
\text { WAD and dizziness }\end{array}$ & $\begin{array}{l}90 \\
27 \\
56\end{array}$ & $\begin{array}{l}91 \\
55 \\
88\end{array}$ & $\begin{array}{l}92 \\
- \\
-\end{array}$ & $\begin{array}{l}71 \\
- \\
-\end{array}$ & $\begin{array}{l}10 \\
0.6 \\
-\end{array}$ & $\begin{array}{l}0.11 \\
1.3 \\
-\end{array}$ & $\begin{array}{l}\text { L'Heureux-Leabeau } \\
\text { et al. [14] } \\
\text { Tjell \& Rosenhall [34] } \\
\text { Kongsted et al. [35] }\end{array}$ \\
\hline
\end{tabular}

oculomotor changes [17]. Patients with vestibular migraine do not typically experience dizziness related to mechanical neck pain or dysfunction.

Labyrinthine concussion is a vestibular disorder that can mimic symptoms of CGD due to the presence of dizziness and cervical neck pain [3]. Distinguishing between CGD and labyrinthine concussion is complicated by the fact that both labyrinthine concussion and CGD can be attributed to trauma. Labyrinthine concussion often includes signs and symptoms similar to those of a peripheral vestibular loss (as described above), including hearing loss, tinnitus and dizziness [18].

Cervical arterial dysfunction (CAD) and whiplash associated disorder (WAD) are non-vestibular pathologies that can mimic CGD. Cervical arterial dysfunction is a term sometimes incorrectly used interchangeably with vertebrobasilar insufficiency (VBI). However, VBI refers only to decreased blood flow in the vertebrobasilar arteries, whereas CAD refers to restricted blood flow in any of the cervical arteries, including the internal carotid arteries [19]. There are many potential underlying causes of CAD, including but not limited to atherosclerosis, thrombosis, pre-existing anatomical anomalies, cervical arterial dissection, vasospasm, and external compromise. The clinician should determine if the patient has any cardiovascular risk factors that may increase their likelihood of CAD, such as hypertension, hypercholesterolemia, blood clotting disorders, diabetes mellitus, smoking, vessel trauma, or history of cardiac or vascular disease [19]. CAD presents as dizziness lasting several minutes that is related to movements of the head on the trunk [19]. If the patient reports dizziness without other CAD symptoms, it is very unlikely that CAD is the cause, as CAD related dizziness presents with only one symptom in less than $1 \%$ of cases [20]. Other symptoms of CAD include severe headache, diplopia, nystagmus, numbness around lips or mouth, dysphagia, dysarthria, and upper motor neuron signs [19].

Whiplash associated disorder develops after a trauma involving rapid acceleration and/or deceleration, most commonly a motor vehicle accident. Patients with WAD typically have low pain tolerance and score high on fear avoidance measures such as the Fear Avoidance Belief 
Table 2 Test descriptions

\begin{tabular}{llll}
\hline Diagnosis & Test & Performance description & Explanation \\
\hline Traumatic Cervical & Canadian & 1) Any high-risk factor present: Age $\geq 65$ years OR & Canadian C-Spine Rule is a tool to help clinicians de- \\
Spine Injury & C-Spine Rule & Dangerous mechanism* of injury OR Paresthesias & cide if radiography should be utilized in patients fol- \\
& in extremities. If YES to any, radiography should & lowing traumatic injury. It is only applicable to \\
& be performed. If NO to all, continue to 2. & patients who are alert (Glasgow Coma Scale \\
& 2) Any low risk factor that allows safe assessment of & score $\geq 15)$ and in stable condition following trauma \\
& range of motion? If NO to all, radiography should & where cervical spine injury is a concern. Canadian C- \\
& be performed; if YES to any, continue to 3. Low & Spine Rule is not applicable in non-trauma cases, for \\
& risk factors defined as: Simple rear-end motor ve- & patients with age < 16 years, during pregnancy, or \\
& hicle collisiont OR Sitting position in emergency & for patients with unstable vital signs, acute paralysis, \\
& department OR Ambulatory at any time OR De- & known vertebral disease, or previous history of cer-
\end{tabular}
layed (not immediate) onset of neck pain OR Ab- vical spine surgery.

$\begin{array}{ll}\text { Upper Cervical } & \text { Alar Ligament } \\ \text { Instability } & \text { Test [45] }\end{array}$

Upper Cervical Instability

Cervical Facet Joint Dysfunction

Cervical Facet Joint Mediated Pain

Cervical Arterial Dysfunction
Test [45] $[39,45]$

Manual Spinal

Palpation for Segmental

CAD Testing

$[22,46]$
3) Able to actively rotate neck $45^{\circ}$ left and right? unable, radiography should be performed. *Fall from elevation $\geq 0.9 \mathrm{~m} \mathrm{(3 \textrm {ft } ) / f i v e ~ s t a i r s , ~ a x i a l ~}$ load to head, motor vehicle collision at high speed (>100 km/h), rollover, ejection, motorized recreational vehicles, bicycle struck, or bicycle collision.

+Excludes: pushed into oncoming traffic, hit by bus or large truck, rollover, and hit by high speed vehicle.

1) Patient assumes sitting or supine position with head slightly flexed to engage the Alar ligament. The clinician assesses the patient's resting symptoms.

2) The clinician firmly stabilizes the spinous process of C2 using a pincer grasp.

3) Either lateral flexion or rotation is passively performed by the clinician (both are performed independently of each other, in either order). While performing these passive movements, the examiner attempts to feel movement of $\mathrm{C} 2$.

4) A positive test is defined by lack of palpable movement of the C2 spinous process during lateral flexion or rotation.

Sharp Purser Test 1) The patient assumes a sitting position with their Examination [30] Tenderness [30] head slightly flexed. The clinician assesses the patient's resting symptoms.

2) The clinician stands to one side of the patient and stabilizes the $\mathrm{C} 2$ spinous process using a pincer grasp.

3) The clinician uses the opposite hand to gently apply an anterior to posterior translation force on the patient's forehead.

4) A positive test is defined by symptom reproduction during forward flexion, decrease in symptoms during posterior translation, or excessive displacement ( $>4 \mathrm{~mm}$ ) during posterior translation.

Patient positioned in prone with neutral cervical spine. Clinician applies posterior to anterior directed force to the articular pillars of the cervical spine bilaterally, one joint at a time. In a study by Schneider, et al., a positive test was defined as patient report of $\geq 3 / 10$ increase in concordant local or referred pain intensity when clinician rated resistance to motion as 'moderate' to 'marked'.

Patient positioned in prone. Clinician palpates deep segmental muscles overlying cervical spine facet joints bilaterally. Schneider, et al. defined a positive test as patient report of $\geq 3 / 10$ increase in concordant local or referred pain intensity rating.

CAD testing should include the following sequential tests:
The purpose of this test is to examine the integrity of the alar ligaments following traumatic injury involving the cervical spine. If the alar ligaments are intact, lateral flexion or rotation of the head should result in palpable contralateral movement of the C2 spinous process. Caution is of utmost importance when administering this test.

This test assesses the integrity of the transverse ligament that maintains the position of the odontoid process relative to $\mathrm{C}$. If the transverse ligament is torn, C1 will translate forward on C2 during flexion, indicating atlantoaxial subluxation. Atlantoaxial subluxation is the most common cervical spine complication of rheumatoid arthritis. Spinal cord compression secondary to atlantoaxial subluxation can result in severe neurological damage, including quadriplegia and fatality. Extreme caution should be used when administering this test.

Cervical facet joint capsules contain several sensory receptors including free nerve endings, mechanoreceptors, A-delta and C-fibers, making the joints nociceptive and sensitive to pressure and mechanical changes.

Segmental muscles overlying painful facet joints often react with tenderness and spasm. Cervical facet joints and the muscles overlying them are innervated by the medial branch of the dorsal rami.

CAD testing involves neck rotation and extension with a stationary body, causing decreased blood 
Table 2 Test descriptions (Continued)

1) While seated, the patient performs end range
active cervical rotation in both directions.
2) While seated, the patient performs active end
range combined cervical extension and rotation
in both directions
3) With patient supine, the clinician brings the
patient into passive end range cervical rotation in
both directions.
4) With patient supine, the clinician brings the
patient into passive end range combined cervical
extension and rotation in both directions.
5) Any position that the patient reports as
provocative.
All positions should be held for a minimum of 10 s,
unless symptoms are provoked sooner. After each
sustained position, the patient should return to
neutral cervical spine position for at least $10 \mathrm{~s}$ to
allow for any latent response to emerge.
Throughout CAD testing, the clinician should
observe the patient's eyes for nystagmus, and the
patient should report any provocation of symptoms.
Positive signs and symptoms include dizziness,
nystagmus, diplopia, loss of consciousness,
diaphoresis, dysphagia, dysarthria, nausea, numbness
around the lips, or other neurological symptoms.
Hypofunction

Peripheral Vestibular Dysfunction

Benign Paroxysmal Positional Vertigo
Vestibular
Head Thrust Test [43] Induced
Head Shaking Nystagmus [47]

Grasp the patient's head firmly with both hands and pitch their head forward $30^{\circ}$ to align the horizontal semicircular canals. Instruct the patient to close their eyes. Passively oscillate the patient's head side to side 20 times at $1-2 \mathrm{~Hz}$. Instruct them to open their eyes just prior to completing the 20 side to side movements. Observe for post-headshake nystagmus.

Dix-Hallpike Test [42]

Head Roll Test

Horizontal Canalilithiasis or Cupulolithiasis

[48] clinician observes the patient's eyes for nystagmus for at least $60 \mathrm{~s}$; there can be a latency period of up to $15 \mathrm{~s}$ before the onset of nystagmus.

The patient is initially positioned in supine with their neck flexed $20^{\circ}$. The clinician quickly rotates the patient's head $90^{\circ}$ to either side and observes for flow in the vertebrobasilar arteries with rotation alone and internal carotid arteries with combined extension and rotation. CAD testing requires cervical extension and rotation passive range of motion that is within normal limits.
Head-Neck Differentiation Test [26-28]
The patient begins seated on a swivel chair. The clinician rotates the chair both while the stabilizing patient's head and the patient reports any the chair without stabilizing the patient's head and provocation of dizziness. The clinician then rotates

While performing head thrusts, observe the patient's eyes to determine whether they are able to maintain ocular fixation on your nose or not. A failure to maintain fixation on the visual target (nose) indicates hypofunction on the side that the thrust was directed toward. A refixation saccade will be visible for patients who are unable to maintain visual fixation. This test is most valid if the thrusts are performed with random timing that does not allow anticipatory compensation.

The direction of the fast phase of nystagmus denotes the side of higher vestibular functioning. Therefore, the side of vestibular hypofunction is on the side contralateral to the direction of the fast phase.

The direction of the nystagmus beats will be on the same side as the involved canal. With right sided BPPV, for example, the fast phase of nystagmus wil beat to the right with a slow saccade back to the left. Patients with posterior canal BPPV will have a positive Dix-Hallpike test and concomitant vertigo. nystagmus for at least $60 \mathrm{~s}$. The clinician slowly returns the patient's head to midline, maintaining neck flexion, then repeats the procedure on other side. Cervicogenic Dizziness towards the affected ear with a slow saccade moving in the opposite direction following the fast the affected ear, the nystagmus beats will be in a geotropic (toward the ground) manner. If the head is maintained in this position, a burst of fast beating nystagmus will occur in an ageotropic (away from the ground) fashion. When the head is rolled away from the affected ear, the nystagmus beats will be less intense and in the geotropic fashion.

Provocation of dizziness with trunk rotation under a stabilized head implicates the cervical spine, whereas dizziness with head and trunk rotation together (en bloc rotation) indicates a vestibular component to the patient's symptoms. If symptoms are provoked in both scenarios, it is likely that CGD and vestibular
Like the Dix- Hallpike, the nystagmus will beat beat of nystagmus. When the head is rolled toward 
Table 2 Test descriptions (Continued)

$\begin{array}{ll} & \text { the patient again reports any provocation of } \\ \text { dizziness. }\end{array}$

Cervicogenic Dizziness

\section{Cervical Neck} Torsion Test [14]

The patient begins seated on a swivel chair and turns their trunk $90^{\circ}$ to the either the right or left, holding for $30 \mathrm{~s}$, then returns their trunk to center The patient then repeats the same process in the opposite direction. Each position, including the center positions, is maintained for $30 \mathrm{~s}$. Throughout the test, the head is stabilized by the clinician and therefore motionless. The clinician also must continuously observe for nystagmus.

Cervicogenic Dizziness, Whiplash Associated Disorder
Cervicocephalic Proprioception and Neck Reposition Sense
Smooth Pursuit Neck Torsion Test (SPNT) [34, 49]
Surface electrodes are placed on the subject's skin just lateral to the eyes bilaterally to record the corneo-retinal potential. The subject begins seated with their cervical spine in neutral position. The subject watches a visual target (LED or laser light) that moves through a $40^{\circ}$ arc at a frequency of $0.2 \mathrm{~Hz}$ with a peak velocity of $20^{\circ}$ per second. The subject is instructed to keep their head still and try not to blink while following the light closely with their eyes. The examiner gently holds the subject's head in place. This process is then repeated with the subject's body rotated $45^{\circ}$ to one side with the head remaining in the same position to create cervical torsion. If $45^{\circ}$ of trunk rotation causes discomfort, the angle can be decreased to symptom free range (minimum of $30^{\circ}$ ). The examiner gently holds the subject's head and trunk in the position. The test is performed to the left and right sides. The mean gain (i.e. the ratio between eye velocity and target velocity) is calculated in all three positions.

Cervical The patient begins seated, facing a wall $90 \mathrm{~cm}$ away, Relocation Test [32] and wearing a head-mounted laser pointer that is centered on a target on the wall. The patient keeps their eyes closed while moving their neck in a specified direction, then back to what they believe to be centered starting position. The patient verbally indicates when they believe they are back to center. The patient repeats this process for right rotation, left rotation, flexion, and extension (in no particular order). dysfunction are comorbid. Dizziness of vertebral origin should be ruled out prior to administration of the Head-Neck Differentiation Test.

Considered positive if nystagmus (excluding spontaneous nystagmus) of more than $2^{\circ}$ per second is observed in any of the four positions (left trunk rotation, neutral rotation, right trunk rotation, neutral rotation).

There is a lack of consensus in the description of proper performance methodology of the SPNT. The methods described are based on the initial study of the SPNT performed by Tjell and Rosenhall in 1998. The SPNT is a test of smooth pursuit eye movement with cervical neck torsion. The SPNT is the average value of the smooth pursuit in both the right and left trunk-rotation positions. The difference between the smooth pursuit and the smooth pursuit with neck torsion values is called the smooth pursuit neck torsion difference. The larger the difference between smooth pursuit with neck torsion and smooth pursuit in neutral, the more likely the patient is suffering from a whiplash associated disorder. The utility of the SPNT as a diagnostic tool for differentiating CGD from WAD has been studied in controlled laboratory trials, with mixed results, but has not yet been studied in a clinical setting.

The mean distance from the actual center to the subjective center is used to calculate the joint position error (JPE) for each movement. An error of $4.5^{\circ}$ is the cutoff point suggesting a failure of head and neck relocalization precision.
Questionnaire (FABQ). Common symptoms of WAD are cervical neck pain and hypersensitivity, decreased cervical ROM, dizziness, tinnitus, and headache [21]. In some cases, the dizziness that accompanies WAD may be CGD. WAD can also be associated with a concussion that occurs during a traumatic injury. Therefore, WAD, concussion, and CGD are not mutually exclusive diagnoses. When a person experiences dizziness as a symptom of concussion and/or WAD, the dizziness can be of cervical origin.

\section{Step 2: Triage}

If the subjective report includes blunt trauma, triage of the cervical spine should first utilize the Canadian CSpine (cervical spine) Rule to determine if radiography is indicated. The criteria for the Canadian C-Spine Rule are detailed in Table 2. The Canadian C-Spine Rule has high sensitivity, and therefore it is very unlikely to incorrectly determine that a patient with a severe cervical spine injury does not require radiography. If the patient reports significant red flag symptoms consistent with CAD, they should be referred for diagnostic imaging to rule out the cervical arteries as a potential cause of dizziness. Clinical tests for cervical instability and $\mathrm{CAD}$ are provocative in nature and therefore should be used sparingly and with utmost caution. Positive results on cervical instability testing or CAD testing indicate a need for immediate medical attention and imaging [22].

If no imaging is warranted based on the Canadian CSpine Rule or significant red flag symptoms of CAD, the clinician should proceed with assessment of cervical range of motion. Cervical ROM is appropriate at this juncture in the triage stage because several tests that the clinician may utilize later in the examination, including vestibular tests discussed in Step 3, have minimum cervical ROM requirements. Furthermore, identifying 
Table 3 Presentation of cervicogenic dizziness and competing diagnoses

\begin{tabular}{|c|c|c|}
\hline Diagnosis & Duration & Signs and symptoms \\
\hline $\begin{array}{l}\text { Acute Vestibular } \\
\text { Loss }\end{array}$ & $\begin{array}{l}\text { Single attack, several attacks, or } \\
\text { persistent for several weeks. }\end{array}$ & Sudden vertigo or dizziness possibly accompanied by tinnitus, diplopia, nausea, vomiting [15]. \\
\hline $\begin{array}{l}\text { Benign } \\
\text { Paroxysmal } \\
\text { Positional Vertigo }\end{array}$ & $\begin{array}{l}\text { A few seconds to several } \\
\text { minutes. }\end{array}$ & Vertigo. Occurs with changes in position relative to gravity [50]. \\
\hline $\begin{array}{l}\text { Central Vestibular } \\
\text { Disorders }\end{array}$ & Several days to weeks. & $\begin{array}{l}\text { Constant vertigo, facial asymmetry, swallowing or speech problems, ptosis, ataxia, } \\
\text { sensation changes, upper motor neuron signs, abnormal head thrust test, direction } \\
\text { changing nystagmus, pure vertical nystagmus, pure torsional nystagmus, a skew } \\
\text { deviation, and other neurological symptoms }[23,51] \text {. }\end{array}$ \\
\hline $\begin{array}{l}\text { Cervical Arterial } \\
\text { Dysfunction }\end{array}$ & Several minutes. & $\begin{array}{l}\text { Dizziness that is typically accompanied by diplopia, numbness around the lips, } \\
\text { nystagmus, ataxia, bilateral neurological symptoms, dysphagia, dysarthria and } \\
\text { headaches. Associated with nausea and vomiting [19]. }\end{array}$ \\
\hline $\begin{array}{l}\text { Cervicogenic } \\
\text { Dizziness }\end{array}$ & Several minutes to hours [3]. & Dizziness and disequilibrium due to changes in cervical spine position [3]. \\
\hline $\begin{array}{l}\text { Labyrinthine } \\
\text { Concussion }\end{array}$ & $\begin{array}{l}\text { Episodically over hours to days } \\
\text { [26]. }\end{array}$ & Cervical neck pain is common. Hearing loss, tinnitus, and dizziness [18]. \\
\hline $\begin{array}{l}\text { Ménière's } \\
\text { Disease }\end{array}$ & $\begin{array}{l}\text { Minutes to hours, rarely longer } \\
\text { than } 24 \mathrm{~h}[12] \text {. }\end{array}$ & $\begin{array}{l}\text { Presents with episodic, intense vertigo, accompanied by aural fullness, tinnitusand fluctuating } \\
\text { hearing loss. Attacks are typically preceded by aura and followed by a period of exhaustion } \\
\text { and generalized dizziness. As Ménière's disease progresses, the hearing loss and tinnitus } \\
\text { intensify and become more persistent, and the acute attacks of vertigo may be replaced by } \\
\text { more chronic problems with dizziness and imbalance }[12,13] \text {. }\end{array}$ \\
\hline $\begin{array}{l}\text { Vestibular } \\
\text { Migraine }\end{array}$ & $4-72 \mathrm{~h}$. & $\begin{array}{l}\text { Vestibular Migraine Diagnostic Criteria (International Headache Society) [17]. } \\
\text { A. At least five episodes involving criteria C and D. } \\
\text { B. A current or past history of Migraine without aura or Migraine with aura. } \\
\text { C. Vestibular symptoms* of moderate or severe intensity, lasting between } 5 \text { min and } 72 \mathrm{~h} \text {. } \\
\text { D. At least } 50 \% \text { of episodes are associated with at least one of the following three migrainous } \\
\text { features: 1) headache with at least two of the following four characteristics: unilateral location } \\
\text { pulsating quality, moderate or severe intensity, aggravation by routine physical activity; } 2 \text { ) } \\
\text { photophobia and phonophobia; } 3 \text { ) visual aura. } \\
\text { E. Not better accounted for by another ICHD-3 diagnosis or by another vestibular disorder. } \\
\text { *Barany Society's Classification of Vestibular Symptoms: } \\
\text { a. spontaneous vertigo: } \\
\text { i. internal vertigo (a false sensation of self-motion) } \\
\text { ii. external vertigo (a false sensation of visual surroundings spinning or flowing) } \\
\text { b. positional vertigo, triggered by a complex or large moving stimulus } \\
\text { c. visually induced vertigo, triggered by a complex or large moving visual stimulus } \\
\text { d. head motion-induced vertigo, occurring during head motion } \\
\text { e. head motion-induced dizziness with nausea }\end{array}$ \\
\hline $\begin{array}{l}\text { Whiplash } \\
\text { Associated } \\
\text { Disorder }\end{array}$ & $\begin{array}{l}\text { Variable. Days to weeks and in } \\
\text { some cases months. }\end{array}$ & $\begin{array}{l}\text { Cervical neck pain and hypersensitivity, decreased cervical range of motion, dizziness, tinnitus, } \\
\text { and headache. Associated with psychological factors, such as low pain tolerance and } \\
\text { fear avoidance [21]. }\end{array}$ \\
\hline
\end{tabular}

limitations or symptom provocation with active or passive cervical ROM is an efficient way for the clinician to gain useful information prior to embarking on more complex vestibular and cervical spine testing. For example, the cervical neck torsion test only discriminates using rotation, so if a patient's dizziness is provoked by extension ROM rather than rotation, the clinician may prioritize other clinical tests over the cervical neck torsion test.

Given that patients being evaluated for CGD present with an unknown cause of dizziness and were often involved in a traumatic event, a neurological screen will likely be indicated. A neurological screen should include an assessment of radicular symptoms, myotomes, dermatomes, deep-tendon reflexes, upper motor neuron signs, and cranial nerve function. Abnormal neurological findings may warrant referral to either a neurologist or emergency care for further evaluation, depending on the severity. Central vestibular disorders can present with a variety of symptoms, ranging from constant vertigo to generalized symptoms of dizziness, and will typically present with red flag signs and symptoms that warrant referral to a physician [23].

If cervical instability, CAD, and neurological dysfunction are ruled out, the clinician should proceed with clinical tests to rule out vestibular pathologies.

\section{Step 3: Vestibular assessment}

If a patient has a history consistent with CGD and has been properly screened in the triage stage, the vestibular system should be assessed next. All patients should have a rudimentary cervical spine examination prior to vestibular 
testing, including subjective report of cervical spine pain established in Step 1, as well as assessment of cervical spine ROM and radicular symptoms in Step 2. The vestibular exam can be modified to limit the head movements to the available cervical ROM. A thorough evaluation of the cervical spine is best performed in Step 4 because first ruling out vestibular dysfunction increases the probability that the cervical spine is the cause of dizziness. With that being said, there is likely to be some overlap between Step 3 and Step 4; the nature of the presenting history, symptoms and signs will dictate the order of evaluation and treatment. In the case of obvious vestibular causes of dizziness (e.g. BPPV, vestibular hypofunction) without acute cervical spine involvement, treatment of the vestibular pathology would be initiated prior to moving on to Step 4 . If there is markedly restricted cervical spine ROM that precludes treatment of the vestibular pathology, then cervical spine assessment and treatment would have to precede (or occur concurrently with) the treatment of the vestibular pathology.

Within the vestibular functioning step, oculomotor evaluation should include evaluation of nystagmus, skew, smooth pursuit, saccades, Dix-Hallpike test, static and dynamic visual acuity, and the vestibulo-ocular reflex (VOR) including VOR cancellation and the head thrust test. The observation of nystagmus is clinically useful to determine if the vestibular system is involved, and the presence of nystagmus during testing can help to rule out CGD.

A horizontal, direction fixed nystagmus is consistent with unilateral peripheral vestibular hypofunction. Patients with unilateral vestibular hypofunction typically have oculomotor signs such as a positive head thrust test or head shaking induced nystagmus, and may have abnormal dynamic visual acuity-these findings would not typically be seen in an individual with CGD. The absence of spontaneous or gaze-evoked nystagmus in room light does not rule out a peripheral vestibular deficit because patients with peripheral vestibular hypofunction can utilize visual fixation to suppress nystagmus. Therefore, utilization of Frenzel lenses allows for more reliable detection of unilateral peripheral vestibular hypofunction as the Frenzel lenses will remove visual fixation. Individuals who have compensated for a unilateral loss will often have no nystagmus in room light, whereas individuals with bilateral vestibular loss generally have no nystagmus in either room light or with visual fixation removed. Nystagmus originating from a central pathology demonstrates a different pattern; the nystagmus will be present in room light and will either persist or diminish when visual fixation is removed. Direction changing nystagmus, pure vertical nystagmus, or torsional nystagmus is consistent with a central vestibular deficit.

Other oculomotor abnormalities, such as saccadic smooth pursuit or saccadic abnormalities, may be seen in patients with central vestibular and central oculomotor deficits. While there have been some reports of abnormal eye movements in cases of WAD, the results from different studies are highly variable $[24,25]$. There is not a single, definitive oculomotor test that is capable of identifying CGD.

Cervicogenic dizziness and dizziness from vestibular disorders can be differentiated using the head-neck differentiation test, which is a variation of the cervical neck torsion test [26-28]. The test is performed with the patient sitting on a swivel chair. Provocation of dizziness with trunk rotation under a head stabilized in space implicates the cervical spine, whereas dizziness with head and trunk rotation together (en bloc rotation) indicates a vestibular component to the patient's symptoms. This test can be performed for both horizontal and pitch plane motions of the head and cervical spine. If symptoms are provoked in both scenarios, it is likely that CGD and vestibular dysfunction are comorbid, and then both the vestibular and cervicogenic components can be addressed.

While static and dynamic balance tests are not diagnostic for vestibular dysfunction, these tests are often abnormal in individuals with vestibular deficits [28, 29]. Studies have also shown that cervical pain can cause decreased standing balance and postural control [8]. Patients with either vestibular dysfunction or CGD may have increased symptoms during a dynamic balance assessment. While not diagnostic for either condition, assessment of static and dynamic balance is important from the perspective of a functional assessment.

Positive results on vestibular tests do not rule out cervicogenic dizziness, as a patient can have two causes of dizziness simultaneously. If a patient is found to have vestibular dysfunction, the clinician may initiate treatment of the dysfunction if it is within their capabilities, as well as refer to an otolaryngolist or neurologist depending on the patient's presenting signs and symptoms for further medical assessment. If treatment of the vestibular impairment does not lead to complete resolution of the patient's symptoms of dizziness, or if the headneck differentiation test indicates cervical and vestibular involvement, the clinician should consider the possibility that the patient has both dizziness of vestibular origin and CGD, and proceed with Step 4.

\section{Step 4: Detailed cervical spine evaluation}

Although cervical range of motion testing and cervical instability testing are most appropriately performed as part of triage, thorough evaluation of the cervical spine should ideally be performed after vestibular testing in order to rule out vestibular dysfunction and thereby narrow the list of potential causes of dizziness. Cervical spine evaluation includes manual spinal examination (MSE) for facet joint dysfunction, palpation for segmental tenderness (PST), assessment of postural alignment, and traction. 
There is no individual test that can reliably diagnose the cervical facet joint as a source of pain. However, in one study, MSE and PST both exhibited high sensitivity (92\% and 94\%, respectively), demonstrating potential utility as screens for cervical facet joint mediated pain [30]. Manual spinal examination should include unilateral posterior to anterior mobilization of cervical facet joints with assessment of pain provocation and resistance to motion. To perform PST, the clinician palpates the muscles over the cervical facet joints and assesses for increased concordant pain. Individuals with CGD commonly present with tight posterior neck muscles and tenderness of both posterior neck muscles and cervical facet joints. In a study by L'Heureux-Leabeau et al. [14], the CGD group was significantly more likely than the BPPV group to experience pain during physical examination of the upper cervical spine and paravertebral muscles.

Postural alignment and control should be assessed because postural impairments are commonly seen in cases of CGD, especially in cases with neck pain from whiplash injury [8]. A reduction of dizziness symptoms in response to cervical traction implicates involvement of the cervical spine and is more consistent with CGD than with vestibular dysfunction [31]. It is best to perform traction with the patient sitting in order to minimize the effect of gravity on the vestibular system.

\section{Step 5: Clinical tests for cervicogenic dizziness}

While CGD is a diagnosis of exclusion and cannot be definitively ruled in with any single test, there are tests that have been demonstrated to be clinically useful. Ruling out competing diagnoses in previous steps will increase the pre-test probability of CGD, thereby increasing the post-test probability when utilizing these clinical tests.

The test with the strongest diagnostic utility to rule in the diagnosis of cervicogenic dizziness is the cervical neck torsion test ( $\mathrm{LR}+$ of 9), which measures nystagmus in response to cervical neck rotation [14]. The cervical relocation test, a measure of joint position error, has good diagnostic value for ruling out the diagnosis of cervicogenic dizziness (LR- of 0.15). The diagnostic value of both the cervical neck torsion test and cervical relocation test are limited by the fact that the likelihood ratios are based on a study comparing only CGD and BPPV. L'Heureux-Leabeau et al. [14] found that the cervical neck torsion test and cervical relocation test are most useful for differential diagnosis of BPPV versus CGD when the results of the two tests were combined. Table 2 describes how to perform the cervical neck torsion test and the cervical relocation test.

Revel and colleagues [32] demonstrated that individuals with chronic neck pain have impaired head relocation after active head rotation. Multiple studies of cervical kinesthetic sense have shown that cervical repositioning errors are greater in cases of WAD that include complaints of dizziness, as opposed to WAD cases without dizziness, especially for tests of cervical rotation [33]. While it is unclear whether these results are due to dizziness or pain, impaired cervical kinesthetic sense is important to consider as one aspect of CGD.

The smooth pursuit neck torsion test (SPNT) is a laboratory test that has been proposed for differentiating CGD from WAD. The SPNT test is a comparison of the gain (the ratio of the eye velocity to the target velocity) of the eye response in neutral versus rotated head positions. One laboratory study found the gain difference to be significantly greater in WAD cases that include dizziness, as compared to WAD cases without dizziness [34]. However, other laboratory trials using the SPNT test have concluded that it is not useful for differentiating CGD from WAD [35]. The reliability, validity and diagnostic accuracy of a clinical version of the SPNT for differential diagnosis of CGD has not been determined. At this point, there is no clinical advantage to using the SPNT test alongside cervical neck torsion testing as both the sensitivity and specificity are higher in cervical neck torsion testing [14]. Therefore, the SPNT test is currently not a clinically useful test for diagnosing CGD.

\section{Study limitations}

It is worth noting that the diagnostic utility of many special tests used for the diagnosis of CGD have been studied by comparing two specific populations. For example, differentiating only between BPPV and CGD or between CGD and WAD. Therefore, this paper is limited by the goal of portraying a comprehensive, generalized clinical thought process by combining the insights of a wide variety of studies, each offering conclusions about specific questions. Each test and technique discussed has its own limitations. For example, the most well-known test for CGD is the head-neck differentiation test, which has not yet been studied for diagnostic utility. The clinical tests are each limited by their scope. For example, the cervical neck torsion test only examines dizziness provocation using rotation, so these tests may not reproduce dizziness in patients with CGD that is provoked by movement into other planes. The tests with the most clinically useful likelihood ratios, the cervical neck torsion test and cervical relocation test, were established in a study comparing only CGD and BPPV, and therefore are not sufficiently validated to be considered independently conclusive measures for ruling CGD in or out in the general population. The value of this framework for the diagnosis of CGD has not yet been validated using a controlled clinical trial. This paper is an amalgamation of the current evidence for 
best-practice in the diagnosis of CGD combined with the opinions of clinical experts (RC).

\section{Conclusions}

Without robust diagnostic tests to definitively diagnose or exclude CGD, it is currently best categorized as a diagnosis of exclusion. To diagnose CGD, masquerading pathologies must be identified and excluded. However, a thorough subjective history and triage screening can narrow the list of potential pathologies. If a patient does not report both dizziness and cervical involvement, CGD is unlikely. CGD is also less likely if the patient reports tinnitus, hearing loss or migraines. Duration of symptoms can further narrow the list of likely pathologies. After obtaining the subjective report, it is sometimes necessary to screen for neck instability and CAD involvement before moving on to clinical tests. Vestibular testing, such as the head-neck differentiation test and Dix-Hallpike maneuver, can then be used to determine if the vestibular system is causing the dizziness. Once vestibular pathologies have been ruled out, the clinician should examine the cervical spine, followed by the cervical neck torsion test and cervical relocation test to help confirm or exclude the diagnosis of CGD. If all other pathologies have been ruled out and the exam results are generally consistent with CGD, the clinician should make the diagnosis of CGD. It is possible for patients to have both CGD and another cause of dizziness, such as WAD or a vestibular pathology. In this scenario, the clinician can be most confident about diagnosing the patient with cervicogenic dizziness after they have thoroughly addressed the comorbidity with appropriate interventions, but dizziness still persists.

\section{Abbreviations}

BPPV: Benign paroxysmal positional vertigo; CAD: Cervical arterial dysfunction; CGD: Cervicogenic dizziness; CTA: Computerized tomography angiography; ERT: Extension-rotation test; FABQ: Fear-avoidance beliefs questionnaire; JPE: Joint position error; LED: Light emitting diode; LR-: Negative likelihood ratio; LR+: Positive likelihood ratio; MRA: Magnetic resonance angiography; MRI: Magnetic resonance imaging; MSE: Manual spinal examination; PST: Palpation for segmental tenderness; PV-: Negative predictive value; PV+: Positive predictive value; ROM: Range of motion; SPNT: Smooth pursuit neck torsion; VBI: Vertebrobasilar insufficiency; VOR: Vestibulo-ocular reflex; WAD: Whiplash associated disorder

\section{Acknowledgements}

We would like to thank Dr. Chad Cook PT, PhD for his assistance with this project.

\section{Funding}

There are no possible sources of financial support, funding, or grants to report. Availability of data and materials.

Data sharing is not applicable to this article as no datasets were generated or analyzed.

\section{Authors' contributions}

The stated authors have met all four criteria for authorship as recommended by International Committee of Medical Journal Editors (ICMJE). All authors listed on the title page have contributed to the research, organizations, and writing of the manuscript, read the final manuscript, attest to the validity and legitimacy of the data and its interpretation, and agree to the submission to Archives of Physiotherapy. All authors read and approved the final manuscript.

\section{Authors' information}

At the time this article was completed, Alexander Reiley, PT, DPT, Frank Vickory, PT, DPT, Sarah Funderburg, PT, DPT, and Rachel Cesario, PT, DPT were all recent graduates of the Doctor of Physical Therapy Program, Class of 2017 at Duke University, Durham, NC 27705, United States. Richard Clendaniel, PT, PhD earned his PhD in Behavioral Neuroscience at the University of Alabama at Birmingham. He completed a 2-year post-doctoral fellowship in Neuro-Otology at The Johns Hopkins University School of Medicine, Department of

Otolaryngology-Head and Neck Surgery. He has authored numerous articles and book chapters on vestibular system neurophysiology, vestibular rehabilitation and cervicogenic dizziness. He is co-editor of the text: Vestibular Rehabilitation (4th edition). He is currently a faculty member in the Duke University Doctor of Physical Therapy program, and he has an adjunct appointment at the University of North Carolina in the Department of Allied Health Sciences, Division of Speech and Hearing Sciences. He also serves on the Medical and Scientific Advisory Board of Vestibular Disorders Association. Dr. Clendaniel has no competing interests to report.

Ethics approval and consent to participate

Not applicable

\section{Consent for publication}

Not applicable

\section{Competing interests}

The authors declare that they have no competing interests.

\section{Publisher's Note}

Springer Nature remains neutral with regard to jurisdictional claims in published maps and institutional affiliations.

Received: 10 February 2017 Accepted: 4 September 2017

Published online: 12 September 2017

\section{References}

1. Ryan GM, Cope S. Cervical vertigo. Lancet. 1955;269:1355-8.

2. Lystad RP, Bell G, Bonnevie-Svendsen M, Carter CV. Manual therapy with and without vestibular rehabilitation for cervicogenic dizziness: a systematic review. Chiropr Man Therap. 2011;19(1):21.

3. Wrisley DM, Sparto PJ, Whitney SL, Furman JM. Cervicogenic dizziness: a review of diagnosis and treatment. J Orthop Sports Phys Ther. 2000;30(12):755-66.

4. Reid SA, Callister R, Katekar MG, Rivett DA. Effects of cervical spine manual therapy on range of motion, head repositioning, and balance in participants with cervicogenic dizziness: a randomized controlled trial. Arch Phys Med Rehabil. 2014;95(9):1603-12.

5. Reid SA, Rivett DA. Manual therapy treatment of cervicogenic dizziness: a systematic review. Man Ther. 2005;10(1):4-13.

6. Morinaka S. Musculoskeletal diseases as a causal factor of cervical vertigo. Auris Nasus Larynx. 2009;36(6):649-54

7. Karlberg M, Magnusson M, Malmstrom EM, Melander A, Moritz U. Postural and symptomatic improvement after physiotherapy in patients with dizziness of suspected cervical origin. Arch Phys Med Rehabil. 1996;77(9):874-82.

8. Kristjansson E, Treleaven J. Sensorimotor function and dizziness in neck pain: implications for assessment and management. J Orthop Sports Phys Ther. 2009;39(5):364-77.

9. Fred HL. The diagnosis of exclusion: an ongoing uncertainty. Tex Heart Inst J. 2013;40(4):379-81.

10. Reneker JC, Clay Moughiman M, Cook CE. The diagnostic utility of clinical tests for differentiating between cervicogenic and other causes of dizziness after a sports-related concussion: An international Delphi study. J Sci Med Sport. 2015;18(4):366-72.

11. Dorland WAN. Dorland's illustrated medical dictionary. 32nd ed. Philadelphia: Saunders; 2011.

12. Haybach PJ, Underwood JL. Ménière's disease: what you need to know. 1st ed. Portland, OR: Vestibular Disorders Association; 1998.

13. Semaan MT, Megerian CA. Ménière's disease: a challenging and relentless disorder. Otolaryngol Clin N Am. 2011;44(2):383-403. 
14. L'Heureux-Lebeau B, Godbout A, Berbiche D, Saliba I. Evaluation of paraclinical tests in the diagnosis of cervicogenic dizziness. Otol Neurotol. 2014;35(10):1858-65

15. Shupert CL. Labyrinthitis and vestibular neuritis. Vestibular Disorders Association. 2013; http://vestibular.org/labyrinthitis-and-vestibular-neuritis. Accessed 22 Oct 2016

16. Furman JM, Balaban CD. Vestibular migraine. Ann N Y Acad Sci. 2015;80:179-87.

17. Headache Classification Committee of the International Headache Society. The International Classification of Headache Disorders, 3rd edition (beta version). Cephalalgia. 2013;33(9):629-808.

18. Choi MS, Shin SO, Yeon JY, Choi YS, Kim J., Park SK. Clinical characteristics of labyrinthine concussion. Korean J Audiol 2013;17(1):13-17.

19. Kerry R, Taylor AJ. Cervical arterial dysfunction assessment and manual therapy. Man Ther. 2006;11(4):243-53.

20. Savitz SI, Caplan LR. Vertebrobasilar disease. N Engl J Med. 2005:352:2618-26.

21. Sterling M. Whiplash-associated disorder: musculoskeletal pain and related clinical findings. J Man Manip Ther. 2011;19(4):194-200.

22. Hutting N, Verhagen AP, Vijverman V, Keesenberg MDM, Dixon G, ScholtenPeeters GGM. Diagnostic accuracy of premanipulative vertebrobasilar insufficiency tests: a systematic review. Man Ther. 2012;18(3):177-82.

23. Furman JM, Whitney SL. Central causes of dizziness. Phys Ther. 2000;80(2):179-87.

24. Janssen M, Ischebeck BK, de Vries J, Kleinrensink GJ, Frens MA, van der Geest JN. Smooth pursuit eye movement deficits in patients with whiplash and neck pain are modulated by target predictability. Spine. 2015;40:1052-7.

25. Ischebeck BK, de Vries J, Van der Geest JN, Janssen M, Van Wingerden $J P$, Kleinrensink GJ, Frens MA. Eye movements in patients with whiplash associated disorders: a systematic review. BMC Musculoskelet Disord. 2016;17(1):441-51.

26. Norre ME. Cervical vertigo. Diagnostic and semiological problem with special emphasis upon "cervical nystagmus". Acta Otorhinolaryngol Belg. 1987;41(3):436-52

27. Fitz-Ritson D. Assessment of cervicogenic vertigo. J Manip Physiol Ther. 1991;14(3):193-8

28. Philipszoon AJ, Bos JH. Neck torsion nystagmus. Pract Otorhinolaryngol (Basel). 1963;25:339-44

29. Whitney SL, Hudak MT, Marchetti GF. The dynamic gait index relates to selfreported fall history in individuals with vestibular dysfunction. J Vestib Res. 2000;10(2):99-105

30. Schneider GM, Jull G, Thomas K, Smith A, Emery C, Faris P, Cook C, Frizzell B, Salo P. Derivation of a clinical decision guide in the diagnosis of cervical facet joint pain. Arch Phys Med Rehabil. 2014;95(9):1695-701.

31. Clendaniel RA, Landel R. Physical therapy management of cervicogenic dizziness. In: Herdman SJ, Clendaniel RA, editors. Vestibular rehabilitation—fourth edition. Philadelphia: F.A. Davis Company; 2014. p. 597-616

32. Revel M, Andre-Deshays C, Minguet M. Cervicocephalic kinesthetic sensibility in patients with cervical pain. Arch Phys Med Rehabil. 1991;72(5):288-91.

33. Heikkila HV, Wenngren BI. Cervicocephalic kinesthetic sensibility, active range of cervical motion, and oculomotor function in patients with whiplash injury. Arch Phys Med Rehabil. 1998:79(9):1089-94.

34. Tjell C, Rosenhall U. Smooth pursuit neck torsion test: a specific test for cervical dizziness. Am J Otol. 1998;19(1):76-81.

35. Kongsted A, Jorgensen LV, Leboeuf-Yde C, Qerama E, Korsholm L, Bendix T. Are altered smooth pursuit eye movements related to chronic pain and disability following whiplash injuries? A prospective trial with one-year follow-up. Clin Rehabil. 2008:22(5):469-79.

36. Stiell IG, Clement CM, McKnight RD, Brison R, Schull MJ, Rowe BH, Worthington JR, Eisenhauer MA, Cass D, Greenberg G, MacPhail I, Dreyer J, Lee JS, Bandiera G, Reardon M, Holroyd B, Lesiuk H, Wells GA. The Canadian c-spine rule versus the NEXUS low-risk criteria in patients with trauma. N Engl J Med. 2003;349:2510-8.

37. Duane TM, Wilson SP, Mayglothling J, Wolfe LG, Aboutanos MB, Whelan JF, Malhotra AK, Ivatury RR. Canadian cervical spine rule compared with computed tomography: a prospective analysis. J Trauma. 2011;71(2):352-5.

38. Petersen B, von Maravic M, Zeller JA, Walker ML, Kompf D, Kessler C. Basilar artery blood flow during head rotation in vertebrobasilar ischemia. Acta Neurol Scand. 1996:94(4):294-301.

39. Uitvlugt $\mathrm{G}$, Indenbaum S. Clinical assessment of atlantoaxial instability using the Sharp-Purser test. Arthritis Rheum. 1988:31(7):918-22.

40. Hutting N, Scholten-Peeters GGM, Vijverman V, Keesenberg MDM, Verhagen AP. Diagnostic accuracy of upper cervical spine instability tests: a systematic review. Phys Ther. 2013;93:1686-95.
41. Kaale BR, Krakenes J, Albrektsen G, Wester K. Clinical assessment techniques for detecting ligament and membrane injuries in the upper cervical spine region - a comparison with MRI results. Man Ther. 2008;13(5):397-403.

42. Halker RB, Barrs DM, Wellik KE, Wingerchuk DM, Demaerschalk BM. Establishing a diagnosis of benign paroxysmal positional vertigo through the Dix-Hallpike and side-lying maneuvers: a critically appraised topic. Neurologist. 2008;14(3):201-4.

43. Schubert MC, Tusa RJ, Grine LE, Herdman SJ. Optimizing the sensitivity of the head thrust test for identifying vestibular hypofunction. Phys Ther. 2004 84(2):151-8.

44. Stiell IG, Clement CM, Grimshaw J, Brison RJ, Rowe BH, Schull MJ, Lee JS, Brehaut J, McKnight RD, Eisenhauer MA, Dreyer J, Letovsky E, Rutledge T, MacPhail I, Ross S, Shah A, Perry JJ, Holroyd BR, Ip U, Lesiuk H, Wells GA. Implementation of the Canadian c-spine rule: prospective 12 centre cluster randomised trial. BMJ. 2009:339:b4146.

45. Cook CE, Hegedus EJ. Orthopedic physical examination tests: an evidencebased approach -2 ${ }^{\text {nd }}$ edition. New Jersey: Pearson Education, Inc.; 2013.

46. Rivett D, Shirley D, Magarey M, Refshauge K. Clinical guidelines for assessing vertebrobasilar insufficiency in the management of cervical spine disorders. Australian Physiotherapy Association. 2006. http://www.physiotherapy.asn. au/DocumentsFolder/Resources_Guidelines_Spine_Disorders_2006.pdf. Accessed 6 June 2017

47. Hain TC, Fetter M, Zee DS. Head-shaking nystagmus in patients with unilateral peripheral vestibular lesions. Am J Otolaryngol. 1987;8(1):36-47.

48. Korres SG, Balatsouras DG. Diagnostic, pathophysiologic, and therapeutic aspects of benign paroxysmal positional vertigo. Otolaryngol Head Neck Surg. 2004;131(4):438-44

49. Treleaven J, Gwendolen J, Low CN. Smooth pursuit neck torsion test in whiplash-associated disorders: relationship to self-reports of neck pain and disability, dizziness, and anxiety. J Rehabil Med. 2005;37(4):219-23.

50. Herdman SJ, Tusa RJ, Zee DS, Proctor LR, Mattox DE. Single treatment approaches to benign paroxysmal positional vertigo. Arch Otolaryngol Head Neck Surg. 1993:119(4):450-4

51. Kattah J, Talkad AV, Wang DZ, Yu-Hsiang H, Newman-Toker DE. HINTS to diagnose stroke in the acute vestibular syndrome: three-step bedside oculomotor examination more sensitive than early MRI diffusion-weighted imaging. Stroke. 2009:40:3504-10.

\section{Submit your next manuscript to BioMed Central and we will help you at every step:}

- We accept pre-submission inquiries

- Our selector tool helps you to find the most relevant journal

- We provide round the clock customer support

- Convenient online submission

- Thorough peer review

- Inclusion in PubMed and all major indexing services

- Maximum visibility for your research

Submit your manuscript at www.biomedcentral.com/submit
C) Biomed Central 